\title{
Use of donor-specific red blood cell transfusions for patients undergoing liver transplantation during the COVID-19 pandemic
}

\author{
Tao $\mathrm{Lv}^{1,2 \#}$, Xi Xu ${ }^{1,2 \#}$, Jiulin Song ${ }^{1,2}$, Yifei Tan ${ }^{1,2}$, Li Jiang ${ }^{1,2}$, Jian Yang ${ }^{1,2}$, Diao He ${ }^{1,2}$, Lingxiang Kong ${ }^{1,2}$, \\ Weiyi Zhang ${ }^{3}$, Panyu Chen ${ }^{4}$, Qiwen Xiang ${ }^{4}$, Tao Zhu ${ }^{3}$, Hong Wu ${ }^{1}$, Tianfu Wen ${ }^{1,2 *}$, Jiayin Yang ${ }^{1,2 *}$ \\ ${ }^{1}$ Department of Liver Surgery, Liver Transplantation Center, West China Hospital of Sichuan University, Chengdu, China; ${ }^{2}$ Laboratory of Liver \\ Transplantation, Frontiers Science Center for Disease-related Molecular Network, West China Hospital of Sichuan University, Chengdu, China; \\ ${ }^{3}$ Department of Anesthesiology, West China Hospital of Sichuan University, Chengdu, China; ${ }^{4}$ Operating Room of West China Hospital, West \\ China School of Nursing, Sichuan University, Chengdu, China \\ Contributions: (I) Conception and design: J Yang, T Lv, X Xu, T Wen, H Wu, T Zhu; (II) Administrative support: J Yang, T Wen, H Wu; (III) \\ Provision of study materials or patients: J Yang, T Wen, H Wu, T Zhu, L Jiang; (IV) Collection and assembly of data: T Lv, X Xu, J Song, Y Tan, D \\ He, J Yang, L Kong; (V) Data analysis and interpretation: T Lv, X Xu, W Zhang, P Chen, Q Xiang; (VI) Manuscript writing: All authors; (VII) Final \\ approval of manuscript: All authors. \\ \#These authors shared first authorship and contributed equally to this work. \\ *These authors shared last authorship and contributed equally to this work. \\ Correspondence to: Jiayin Yang, MD; Tianfu Wen, MD. No. 37 Guoxue Alley, Wuhou District, Chengdu 610041, China. \\ Email: doctoryjy@scu.edu.cn; wentianfu@scu.edu.cn.
}

Background: Increased risks have been found for patients undergoing liver transplantation due to the blood supply shortage following the ongoing coronavirus disease 2019 (COVID-19) pandemic. Hence, exploring a method to alleviate this dilemma is urgent. This phase I, nonrandomized, prospective trial aimed to evaluate the safety and feasibility of using donor-specific red blood cell transfusion (DRBCT) as an urgent measurement to alleviate the blood supply shortage in deceased donor liver transplantation (DDLT).

Methods: The outcomes of 26 patients who received DRBCT and 37 patients in the control group who only received 3rd party packed red blood cells (pRBCs) transfusion between May 2020 and January 2021 were compared.

Results: Patients receiving DRBCT did not develop transfusion-related complications, and the incidence of postoperative infection was similar to that in the control group ( $23.1 \%$ vs. $18.9 \%, \mathrm{P}=0.688$ ). Because the patients received the red blood cells from organ donors, the median volume of intraoperative allogeneic red blood cell transfusion from blood bank was 4.0 U (IQR 1.1-8.0 U) in the DRBCT group, which is significantly lower than that $(7.5 \mathrm{U}$, IQR $4.0-10.0 \mathrm{U})$ in the control group $(\mathrm{P}=0.018)$. The peak aspartate aminotransferase (AST) level was significantly lower in the DRBCT group than in the control group $(\mathrm{P}=0.008)$ and so were the AST levels in the first two days after the operation $(\mathrm{P}=0.006$ and $\mathrm{P}=0.033)$.

Conclusions: DRBCT is a safe and effective procedure to lower the need for blood supply and is associated with a reduction in AST levels after transplantation. DRBCT is beneficial to patients receiving life-saving transplantation without sufficient blood supply during the COVID-19 pandemic.

Keywords: Coronavirus disease 2019 (COVID-19) pandemic; Deceased donor liver transplantation (DDLT); Blood supply shortage; donor-specific red blood cell transfusion (DRBCT)

Submitted May 13, 2021. accepted for publication Jul 09, 2021.

doi: $10.21037 / \mathrm{hbsn}-21-190$

View this article at: https://dx.doi.org/10.21037/hbsn-21-190 


\section{Introduction}

With an increasing number of available livers from donation after circulatory death (DCD) donors and donation after brain death (DBD) donors, recently, deceased donor liver transplantation (DDLT) has become a mainstay for treating end-stage liver diseases in many countries $(1,2)$. Considering the facts of preoperative anemia, coagulation disorders, reduced platelet count, and the complexity of the operation, there is a high demand for intraoperative blood products in liver transplantation patients (3).

The ongoing coronavirus disease 2019 (COVID-19) pandemic has many unfavorable impacts on implementing DDLT globally (4-6), one of which is the shortage of blood supply resulting from the sharp decline in blood donation and other reasons (7). The lack of blood supply increases intraoperative risks. Therefore, it is imperative to explore a method that can alleviate the blood supply crisis following the COVID-19 pandemic.

Donor-specific transfusion (DST), a method that transfers donor blood into recipients, was first reported by Newton and Anderson in 1973 (8). In their study, four patients received donor-specific leukocyte transfusion to moderate their immune response (8). Later, Cochrum et al. (9) demonstrated that whole blood transfusion from a living donor before kidney transplantation could improve the graft survival rate. Consistently, other studies involving both living donor transplantations and cadaveric kidney transplantations further demonstrated the effective role of immune response modification of DST in recipients (10-14). However, subsequently, due to the advance in immunosuppressive regimen, the significance of DST became diminished $(15,16)$ and the number of reports on DST gradually decreased.

Till now, few reports have addressed the safety and feasibility of DST in DDLT. Donor-specific red blood cell transfusion (DRBCT), which uses autologous blood recovery system to complete the donor blood preparation and then transfers it into recipients, could be a partial substitute for $3^{\text {rd }}$ party packed red blood cells (pRBCs) transfusion in an emergency. Theoretically, since the majority of patients receiving liver allografts, the transfusion complications could be avoided due to all recipients received $\mathrm{ABO}$-compatible transfusion. If this method was safe and effective, it was much beneficial for implementation of transplantation and thus avoiding the unnecessary discarding of donor livers due to the blood supply shortage during the COVID-19 pandemic. However, whether DRBCT will potentially increase the risk of early postoperative infection in recipients or its influences on liver function and postoperative complications remain unknown. To address these questions, we initiated a prospective clinical trial to study the use of DRBCT in patients who received DDLT without sufficient banked blood supply. Here, we share our experience in applying DRBCT in 26 DDLT recipients. We present the following article in accordance with the TREND reporting checklist (available at https://hbsn. amegroups.com/article/view/10.21037/hbsn-21-190/rc).

\section{Methods}

\section{Study design}

This phase I, nonrandomized, prospective trial aimed to establish a safety and efficacy profile for DDLT patients who received intraoperative DRBCT by comparing the outcomes with those of patients who received only $3^{\text {rd }}$ party pRBCs transfusion in the same period. The trial was conducted in accordance with the Declaration of Helsinki (as revised in 2013). The study was approved by the Ethics Committee of West China Hospital of Sichuan University (No.: 2020-166) and registered with the Chinese Clinical Trial Registry (ChiCTR2000041375). Written informed consent was obtained from each donor and recipient.

\section{Patient and donor selection}

Since January 1, 2015, all Chinese hospitals have stopped using organs from executed prisoners (17). All donors have to be identified as Chinese category I donors, which equal to DBD donors (18). Donor screening involves a review of social and medical history, including travel, sexual history, environmental exposures, previous infections, and drug abuse. Before procurement, we cultivated donor blood, urine, and sputum and performed the metagenomic nextgeneration sequencing (mNGS) for donor blood to detect any potential infections. Serological antibody tests for cytomegalovirus (CMV), hepatitis B virus (HBV), hepatitis $\mathrm{C}$ virus (HCV), human immunodeficiency virus (HIV), and syphilis were also performed, as well as nucleic acid test for $\mathrm{HBV}, \mathrm{HCV}, \mathrm{HIV}$ and CMV. Blood salvage was allowed in donors meeting the following criteria:

(I) Negative for RNA and antibody detections of COVID-19;

(II) Donor families' consent for blood collection;

(III) Age of more than 18 years; 
(IV) Donate liver and kidneys only;

(V) Negative for a blood culture test;

(VI) Negative for a sputum culture test or positive culture of samples with no clinical, laboratory, or radiological signs but except multi-drug resistant bacteria;

(VII) Negative for CMV DNA tests;

(VIII)No transfusion-transmitted infections, including HIV, HBV, HCV, and syphilis;

(IX) No bacterial, fungal, viral or parasitic infections were detected by mNGS;

(X) Total intensive care unit (ICU) stay $<7$ days.

All adult recipients undergoing DDLT were included, except those who accepted unconventional (ABOincompatible, repeated, partial, or combined) liver transplantation or who showed signs of infections within one week prior to transplantation. In addition to the above criteria, DRBCT would be performed in recipients meeting the following criteria:

(I) Insufficient banked blood;

(II) A negative cross-match test;

(III) The CMV serostatus of donors and recipients $(\mathrm{D} / \mathrm{R})$ was at low $(\mathrm{D}-/ \mathrm{R}-)$ or moderate risk $\left(\mathrm{D}_{ \pm} /\right.$ $\mathrm{R}+$ ), according to the guidelines (19);

(IV) Exhibiting any one of the following indications for transfusion: (i) hemoglobin (HGB) $<70 \mathrm{~g} / \mathrm{L}$; (ii) rapid intraoperative blood loss exceeding $1,000 \mathrm{~mL}$; or (iii) unstable intraoperative blood pressure due to blood loss.

\section{Blood collection and storage}

Donor's blood salvage was performed during organ procurement. As shown in Figure 1, inferior vena cava (IVC) catheterization was performed, through which donor blood was drawn by the Autologous Blood Recovery System (3000P, Beijing Jingjing Medical Equipment Co., Ltd.). The blood reservoir and collecting tubes were pre-rinsed with the anticoagulant solution $(25,000 \mathrm{U}$ heparin/500 mL saline) before drawing blood. The withdrawal continued until hemodynamic instability occurred and was followed by cold perfusion. Blood pressure and oxygen saturation were closely monitored during the blood collection process to prevent hypotension or insufficient perfusion of vital organs. Maintenance measurements such as rehydration were taken whenever necessary. And we tried to complete the collection within 3 minutes and maintained a systolic blood pressure above $70 \mathrm{mmHg}$.

After collection, blood was centrifuged at 5,600 rpm using the Autologous Blood Recovery System to remove the plasma and buffy coat. Every $250 \mathrm{~mL}$ of RBCs was then washed with $1,000 \mathrm{~mL}$ of saline. After washing, the supernatant was removed, and RBCs were mixed with an anticoagulant solution (containing $3.27 \mathrm{~g}$ citric acid and $26.3 \mathrm{~g}$ sodium citrate per liter) at a 6:1 ratio in disposable plastic blood bags. The blood was stored at $4^{\circ} \mathrm{C}$ and shaken every $30 \mathrm{~min}$. DRBCT was performed with leukocyte depletion filter (FTS-RC102, Nanjing Shuangwei Biotechnology Co., Ltd.) during transplantation if there were indications for RBC transfusion.

\section{Endpoints}

All patients were monitored for at least 3 months. The primary endpoint was postoperative infectious complications within 1 month. The incidence, severity, and timing of any infections (bacterial, fungal, and viral) in both groups were recorded. Standard criteria were used for the definition of infection as previously reported (20).

The secondary endpoints included other transfusionrelated complications, the 30-day patient and graft survival rates, liver enzymes, bilirubin, international normalized ratio (INR), creatinine (CREA), and T-lymphocyte subsets of recipients. The definition of transfusion-related complications has been described in a previous review (21).

\section{Intraoperative management and posttransplant care}

All liver procurements were performed identically at West China Hospital and flushed with histidine-tryptophanketoglutarate solution. All patients underwent either conventional or piggyback liver transplantation. Third party pRBCs were transfused based on the indications described above until the concentration of HGB reached $8.0 \mathrm{~g} / \mathrm{dL}$. Likewise, fresh frozen plasma, platelets, and cryoprecipitate storage were separately transfused based on corresponding indications. In order to reduce the amount of intraoperative blood transfusion, some anticoagulants and intraoperative blood salvage autotransfusion (just for patients without tumor) were routinely applied.

For the immunosuppressive regimen of early postoperative, all subjects received triple therapy with methylprednisolone, tacrolimus, and mycophenolate mofetil (MMF). Methylprednisolone $(500 \mathrm{mg})$ was given before the skin incision and at the anhepatic phase. Another $200 \mathrm{mg}$ was given on the first day after the operation, followed by progressively decreasing daily doses until withdrawal for 


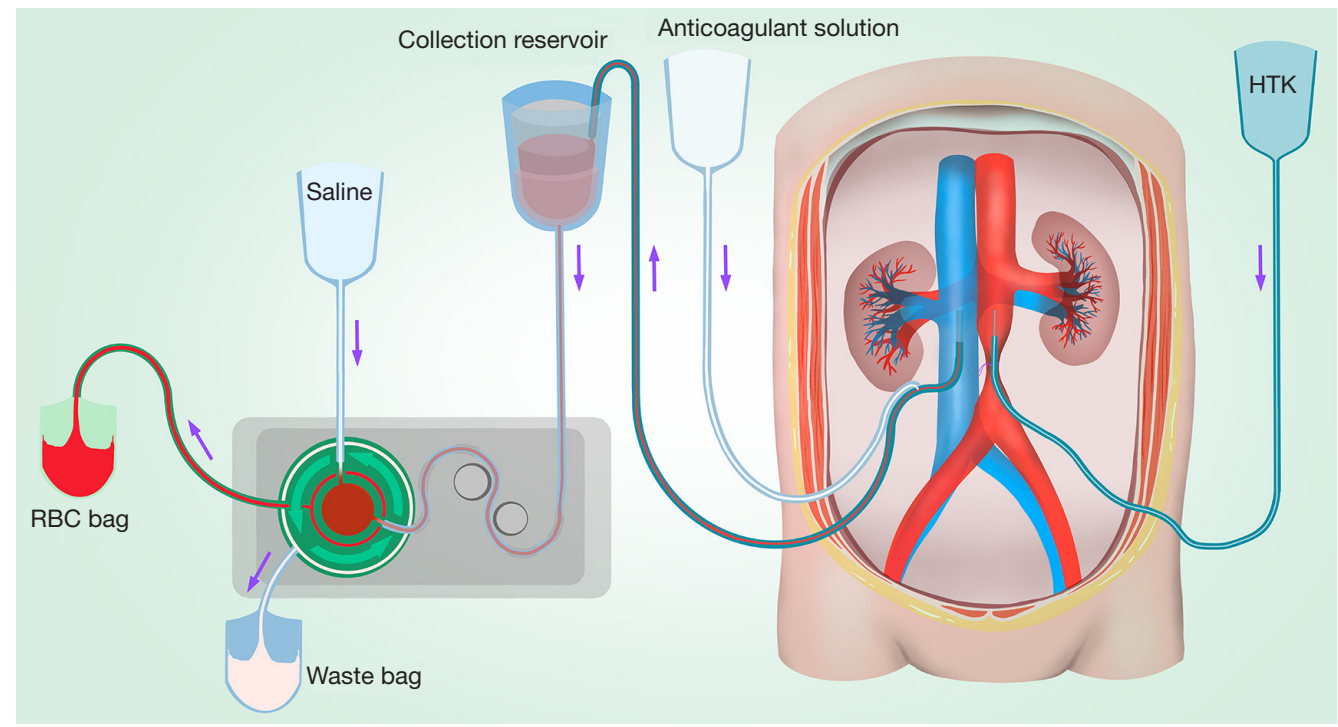

Figure 1 The blood collection pattern during organ procurement. RBC, red blood cell; HTK, histidine-tryptophan-ketoglutarate solution.

2 weeks. Tacrolimus was administered on the first day after surgery with an initial dose of $0.05-0.10 \mathrm{mg} / \mathrm{kg} / \mathrm{d}$ and then subsequently adjusted according to the blood concentration and liver function. MMF was administered on the first day after surgery at a dose of $500 \mathrm{mg}$ twice a day.

The strategy of perioperative infection prevention involved the routine administration of third-generation cephalosporins during the operation and their continuous application for 3 days after the operation, and administration of caspofungin for 1 week. For subjects who tested positive for CMV DNA after the operation, ganciclovir was given at a dosage of $250 \mathrm{mg}$ every 12 hours until virus eradication was achieved but for no less than 2 weeks.

\section{Statistical analysis}

All continuous variables conforming to a normal distribution are expressed as the mean \pm standard deviation (SD) and were compared by Student's $t$-test. Continuous variables that are not normally distributed are presented as the median (interquartile range, IQR) and were compared by the Mann-Whitney $\mathrm{U}$ test. Categorical data are expressed as percentages and were compared by the chi-squared test or Fisher's exact test. A generalized estimating equation (GEE) was used for postoperative laboratory examinations. When $\mathrm{P}<0.05$, the difference was considered statistically significant. Each test was two-tailed. All statistical analyses were performed using $\mathrm{R}$ software version $2.12 \mathrm{x}$ (The $\mathrm{R}$
Foundation for Statistical Computing, Vienna, Austria).

\section{Results}

\section{Donor and recipient characteristics}

In total, 63 out of 75 adult patients who underwent DDLT between May 2020 and January 2021 were enrolled according to the study criteria. All livers were identified as Chinese category I donation type, which equals to DBD donors (18). Twenty-six patients (41.3\%) receiving DRBCT composed the DRBCT group, while the other 37 patients (58.7\%) composed the control group. The median age of the donors in the DRBCT group was 48.5 years (IQR $37.0-56.0$ years), among which 23 (88.5\%) were male. The median age of the donors in the control group was 48.0 years (IQR 37.5-56.0 years), among which 26 (70.3\%) were male. No significant difference was observed between the two groups. The median length of admission to the ICU of the donors in the DRBCT group was 3.5 days (IQR 2.8-5.0 days) versus 4.0 days (IQR 2.0-7.0 days) for the donors in the control group $(\mathrm{P}=0.163)$. Before surgery, the mean HGB level of the donors in the DRBCT group was $105.31 \pm 19.25 \mathrm{~g} / \mathrm{L}$, and the median white blood cell (WBC) count was $11.76 \pm 3.88 \times 10^{9} / \mathrm{L}$. Additionally, no donors showed any signs of infections through our screening. Likewise, none of the recipients in the DRBCT group were at high risk of $\mathrm{CMV}$ infection. A summary that compares the donor and recipient characteristics between the DRBCT group and 
the control group is shown in Table 1 and demonstrates no significant differences between the two groups.

\section{Detailed characteristics of the DRBCT group}

The mean volume of collected donor whole blood was $1,433 \pm 422 \mathrm{~mL}$, and the mean volume of whole blood per kilogram of donor was $23.26 \pm 6.6 \mathrm{~mL} / \mathrm{kg}$. After centrifugation and washing, the median volume of the concentrated RBCs was $500 \mathrm{~mL}$ (IQR 437.5-750 mL), which accounted for 53\% (IQR 32.75-81.25\%) in the total RBC needed for transfusion. And all of these concentrated RBCs were applied during the operation. The mean HGB level in concentrated RBCs was $186.3 \pm 16.7 \mathrm{~g} / \mathrm{L}$, and the median storage time of the blood was $312 \mathrm{~min}$ (IQR 273-381 min). As shown in Table 2, 21 (80.8\%) out of 26 DRBCT patients also donated kidneys, and there was no delayed graft function (DGF) that occurred after kidney transplantation. Similarly, no transfusion-related complications occurred in the DRBCT group.

\section{Intraoperative and postoperative results of the patients}

As shown in Table 3, a significant reduction in intraoperative $3^{\text {rd }}$ party pRBCs transfusion was observed in the DRBCT group compared to the control group (4.0 vs. $7.5 \mathrm{U}$, $\mathrm{P}=0.018$ ). Considering the postoperative outcomes, the two groups had similar lengths of ICU stay and hospital stay. Similarly, there was no significant difference in the occurrence of postoperative infection within 1 month (DRBCT group vs. control group, $23.1 \%$ vs. $18.9 \%$, $\mathrm{P}=0.688$ ) or postoperative complications. None of the recipients had complications related to blood transfusions in either group. No deaths occurred within 30 days after surgery in the DRBCT group. However, 2 (5.4\%) subjects in the control group died due to multiple systemic organ failure. Among them, the preoperative MELD score of patient 1 was 28 points, and that of patient 2 was 40 points.

\section{Postoperative examination results}

As shown in Table 3, the peak level of alanine aminotransferase (ALT) was not significantly different between the two groups. However, the peak level of aspartate aminotransferase (AST) in the DRBCT group was significantly lower than that in the control group $(\mathrm{P}=0.008)$. Moreover, the level of AST was lower in the DRBCT group in the first two days after the operation (Figure 2A). Other postoperative biochemical results such as total bilirubin
(TB), ALT, alkaline phosphatase (ALP), gamma-glutamyl transpeptidase (GGT), lactate dehydrogenase (LDH), CREA, and INR were similar between two groups (Figure 2B,C,D,E,F,G,H).

The two groups of patients had similar ratios of peripheral blood CD4+ $\mathrm{T}$ cells and CD8+ $\mathrm{T}$ cells on days $0,7,14$, and 28 after the operation (Figure $3 A, B$ ). Furthermore, as shown in Figure $3 C$, the CD4+:CD8+ ratio was also comparable between the two groups at each time point.

\section{Discussion}

In this phase I prospective study, we first indicated the safety and feasibility of using DRBCT through a series of 26 DDLT patients based on a strict screening and standard procedure. None of the patients receiving DRBCT developed any transfusion-related complications, and the occurrence of postoperative infections within 1 month was similar to that in the control group. The amount of $3^{\text {rd }}$ party pRBCs transfusion in the DRBCT group was significantly less than that in the control group. In addition, we surprisingly found that patients in the DRBCT group had lower peak AST levels in the early posttransplant period, and the detail mechanism deserved further study.

Despite DST was first reported in 1973 (8), no studies have reported its effectiveness in alleviating the blood supply shortage or its safety and efficacy for DDLT. Most of the previous reports on DST involved whole blood; however, the effect of cytokines or other small molecules in the plasma of DBD donor blood was unclear and might be a potential risk. Therefore, we focused on RBC transfusion, also because alternatives to plasma (e.g., human prothrombin complex) were available during the blood supply crisis period.

In this study, we used autologous blood recovery system to complete the blood preparation, which has been routinely used in emergency and selected surgeries (22). Blood clots and impurities in donor blood were removed, and approximately $60 \%$ of leucocytes were depleted. After washing and centrifugation, the median volume of the concentrated RBCs was approximately $500 \mathrm{~mL}$. The mean HGB of the concentrated RBCs was $186.3 \pm 16.7 \mathrm{~g} / \mathrm{L}$. It is of great interest that the median volume of $3^{\text {rd }}$ party pRBCs transfusion in the DRBCT group was significantly smaller than that in the control group, which revealed a decreased requirement for $3^{\text {rd }}$ party $\mathrm{pRBCs}$ transfusion among patients who receive DRBCT. Our results preliminarily 
Table 1 Baseline data of donors and recipients

\begin{tabular}{|c|c|c|c|}
\hline Variable & DRBCT group & Control group & $P$ value \\
\hline \multicolumn{4}{|l|}{ Donors } \\
\hline Age, years, median [IQR] & $48.5[37.0-56.0]$ & $48[37.5-56.0]$ & 0.605 \\
\hline Male, n (\%) & $23(88.5)$ & $26(70.3)$ & 0.087 \\
\hline $\mathrm{BMI}, \mathrm{kg} / \mathrm{m}^{2}$, mean $\pm \mathrm{SD}$ & $22.45 \pm 3.06$ & $22.37 \pm 3.78$ & 0.932 \\
\hline Cerebrovascular accident & $8(30.8)$ & $19(51.4)$ & \\
\hline Trauma & $16(61.5)$ & $15(40.5)$ & \\
\hline Anoxia & $2(7.7)$ & $3(8.1)$ & \\
\hline $\mathrm{HGB}, \mathrm{g} / \mathrm{L}$, mean $\pm \mathrm{SD}$ & $105.31 \pm 19.25$ & $114.19 \pm 38.12$ & 0.279 \\
\hline $\mathrm{TB}, \mu \mathrm{mol} / \mathrm{L}$, median [IQR] & $13.6[11.1-16.5]$ & $13.0[8.4-18.8]$ & 0.691 \\
\hline AST, IU/L, median [IQR] & $58.5[34.5-134.5]$ & $46.0[29.0-110.5]$ & 0.553 \\
\hline ALT, IU/L, median [IQR] & $29.0[19.8-64.5]$ & $28.0[17.5-93.0]$ & 0.701 \\
\hline $\mathrm{INR}$, mean $\pm \mathrm{SD}$ & $1.26 \pm 0.26$ & $1.25 \pm 0.24$ & 0.927 \\
\hline Serum $\mathrm{Na}+, \mathrm{mmol} / \mathrm{L}$, median [IQR] & $157.8[145.8-162.1]$ & $149.7[145.2-164.4]$ & 0.410 \\
\hline HBV-DNA $\geq 10^{3} \mathrm{IU} / \mathrm{mL}, \mathrm{n}(\%)$ & $0(0.0)$ & $3(8.1)$ & 0.375 \\
\hline \multicolumn{4}{|l|}{ Recipients } \\
\hline Age, years, mean $\pm S D$ & $49.62 \pm 9.27$ & $48.10 \pm 9.10$ & 0.522 \\
\hline $\mathrm{HBV}+\mathrm{HCV}$ & $0(0.0)$ & $1(2.7)$ & \\
\hline With tumors, yes, n (\%) & $12(46.2)$ & $16(43.2)$ & 0.819 \\
\hline MELD score, median [IQR] & 20.5 [12.0-29.5] & $16.0[9.5-25.5]$ & 0.318 \\
\hline Child-Pugh score, median [IQR] & $10.0[8.0-12.0]$ & $9.0[8.0-11.5]$ & 0.336 \\
\hline Risk of CMV infection, $\mathrm{n}(\%)$ & & & 0.382 \\
\hline High & $0(0.0)$ & $3(8.1)$ & \\
\hline Intermediate & $25(96.2)$ & $33(89.2)$ & \\
\hline Low & $1(3.8)$ & $1(2.7)$ & \\
\hline Operation time, min, median [IQR] & $431[374-466]$ & $407[358-466]$ & 0.802 \\
\hline Anhepatic phase, min, median [IQR] & $69[53-78]$ & $63[56-75]$ & 0.764 \\
\hline CIT, min, median [IQR] & $340[271-380]$ & $330[279-416]$ & 0.748 \\
\hline
\end{tabular}

IQR, interquartile range; SD, standard deviation; DRBCT, donor-specific red blood cell transfusion; BMI, body mass index; ICU, intensive care unit; HGB, hemoglobin; PLT, platelet; WBC, white blood cell; TB, total bilirubin; AST, aspartate aminotransferase; ALT, alanine aminotransferase; INR, international normalized ratio; HBV-DNA, hepatitis B virus DNA; HBV, hepatitis B virus; HCV, hepatitis C virus; MELD, model for end-stage liver disease; CMV, cytomegalovirus; CIT, cold ischemia time. 
Table 2 Detailed characteristics for DRBCT group

\begin{tabular}{|c|c|c|c|c|c|c|c|c|c|c|c|c|c|}
\hline Case & \multicolumn{5}{|c|}{ Characteristics of blood from donor } & \multicolumn{6}{|c|}{ Volume of intraoperative blood transfusion } & $\begin{array}{l}\text { Combined } \\
\text { with kidney } \\
\text { donation }\end{array}$ & $\begin{array}{l}\text { DGF of kidney } \\
\text { transplantation }\end{array}$ \\
\hline 1 & 1,000 & 22.22 & 250 & 181 & 329 & 1,000 & - & - & - & - & 100 & Yes & No \\
\hline 3 & 1,600 & 22.86 & 500 & 187 & 310 & - & - & - & - & - & 100 & Yes & No \\
\hline 4 & 1,700 & 26.15 & 500 & 219 & 301 & - & 10 & 800 & - & 1 & 29 & Yes & No \\
\hline 5 & 900 & 18.37 & 250 & 197 & 276 & - & 8 & 800 & - & - & 20 & No & - \\
\hline 6 & 1,800 & 32.73 & 750 & 154 & 444 & - & - & 950 & - & - & 100 & Yes & No \\
\hline 9 & 1,450 & 24.17 & 500 & 185 & 287 & 1,000 & 8 & 900 & 20 & - & 33 & Yes & No \\
\hline 10 & 1,900 & 29.23 & 750 & 192 & 220 & - & 4 & 600 & - & - & 60 & Yes & No \\
\hline 11 & 700 & 11.67 & 250 & 186 & 492 & - & - & 800 & - & - & 100 & No & No \\
\hline 12 & 1,500 & 29.41 & 500 & 191 & 378 & - & 1.5 & 400 & - & - & 73 & Yes & No \\
\hline 13 & 1,100 & 14.67 & 500 & 189 & 312 & 800 & 13.5 & 1,600 & 10 & - & 23 & Yes & No \\
\hline 14 & 2,000 & 30.77 & 750 & 190 & 330 & 600 & 9 & 950 & - & - & 40 & Yes & No \\
\hline 15 & 1,400 & 21.54 & 500 & 182 & 313 & - & - & 800 & - & - & 100 & Yes & No \\
\hline 16 & 1,900 & 29.23 & 750 & 167 & 478 & - & 5 & 350 & - & - & 55 & Yes & No \\
\hline 22 & 800 & 26.67 & 250 & 212 & 231 & 1,400 & 8 & 400 & - & - & 20 & Yes & No \\
\hline 23 & 2,200 & 30.14 & 1,000 & 164 & 300 & 1,400 & 3 & - & - & - & 73 & Yes & No \\
\hline 24 & 750 & 11.54 & 250 & 183 & 189 & 250 & 4 & 600 & - & - & 33 & Yes & No \\
\hline 25 & 1,700 & 21.25 & 750 & 176 & 389 & - & 2 & - & - & - & 75 & Yes & No \\
\hline 26 & 1,200 & 16.00 & 550 & 189 & 312 & - & 8 & 1,250 & - & - & 33 & No & - \\
\hline
\end{tabular}

WB, whole blood; DRBCT, donor-specific red blood cell transfusion; HGB, hemoglobin; RBC-S, red blood cell suspension; DGF, delayed graft function.

demonstrated that DRBCT works and was capable of serving as an effective supplement to blood banks to a certain extent during the COVID-19 pandemic.

However, it is worth noting that during blood collection, avoiding hypotension and the insufficient perfusion of organs is of vital importance. First, we tried to complete the collection within 3 minutes to ensure the organ was not under the condition of hypoxia and ischemia for a long time. In addition, we closely monitored the vital signs of the donor, and a series of maintenance measures, such as rehydration, were taken when necessary. In the case of donor hemodynamic instability and hypotension, we instantly stopped blood collection and started cold perfusion to obtain organs, and the reason for this was that whether the autologous blood recovery system can completely clear the organ preservation solution remained unknown. Our 
Table 3 Intraoperative and postoperative data of the patients

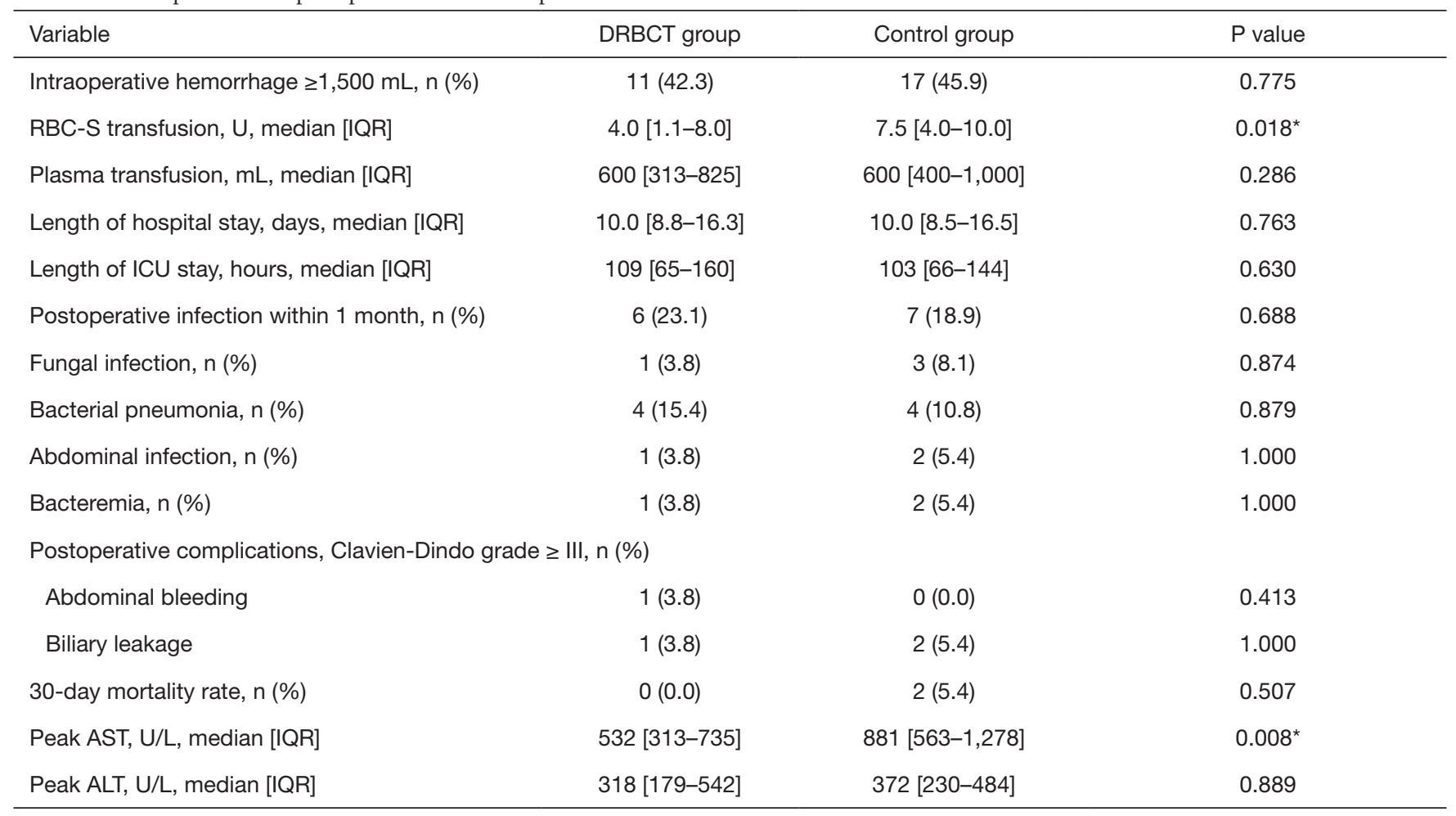

*, $\mathrm{P}<0.05$. IQR, interquartile range; DRBCT, donor-specific red blood cell transfusion; RBC-S, red blood cell suspension; ICU, intensive care unit; CMV, cytomegalovirus; AST, aspartate aminotransferase; ALT, alanine aminotransferase.

results showed that collecting up to approximately $1,400 \mathrm{~mL}$ of whole blood would not lead to severe adverse events caused by organ ischemia. Moreover, there was no DGF in patients who underwent concurrent kidney transplants. At present, there is no experience in collecting blood from multiorgan donors, such as joint cardiopulmonary donation. How to avoid increasing organ ischemia injury in the process of blood collection still needs further research.

In order to guarantee the safety of DRBCT, we also used the leukocyte depletion filter to further remove microclots, impurities, and WBC from the blood. According to the manufacturer's specifications, the filter is capable of producing filtrate containing fewer than $1 \times 10^{6}$ leukocytes per $400 \mathrm{~mL}$ of blood, and the post-filtration RBC recovery rate not less than $94.3 \%$. The residual WBC were also detected and all of them met the above criteria. In this study, no transfusion-related complications, such as febrile non-hemolytic transfusion reaction, allergies and hemolytic reactions, were observed in patients in the DRBCT group. This result may be caused by the application of the leukocyte depletion filter and our rigorous preoperative donor and recipient cross-matching test. Additionally, another reason may be that the recipients were anesthetized and given immunosuppressants and methylprednisolone, which suppress the symptoms of some transfusion-related complications during the transfusion.

Another main concern with the patients in the DRBCT group is the increased risk of donor-derived infections. Though the reported rates of donor-derived infections have decreased to less than $1 \%$ due to the development of donor screening and management, the transmission of an infection could be life-threatening once it occurs (23). Using DRBCT may increase the transmission risk in recipients. Moreover, the donor's blood could also be contaminated during collection, processing, or transfusion. Thus, in this study, several measures were taken to reduce the risk of donor-derived infections, of which donor screening was the first-line prevention. First, we ensured that the donors were healthy adults and met the criteria of China for blood donation before being struck by a lifethreatening crisis. Since bacterial and fungal infections are common complications after DDLT, blood collection from 
A

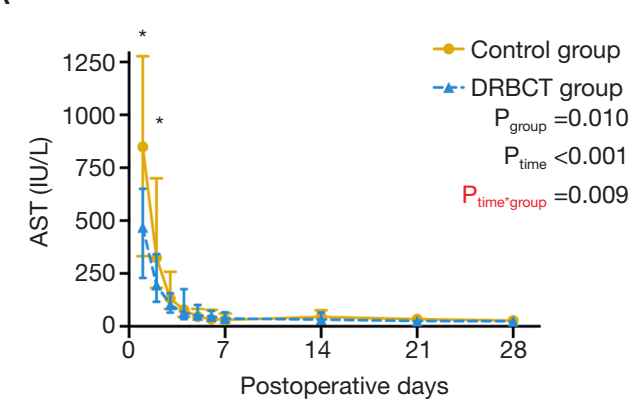

C

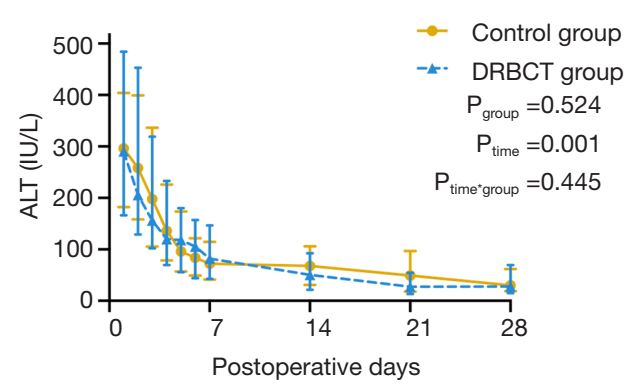

E

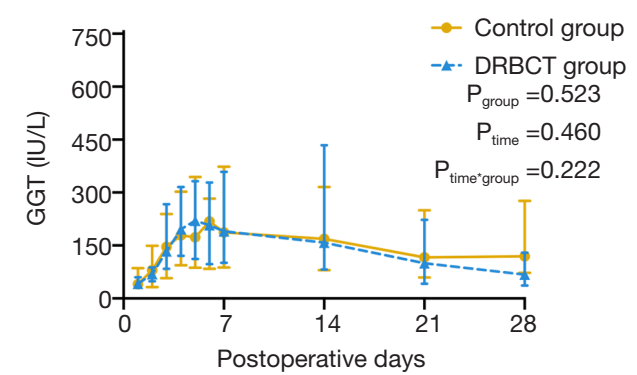

G

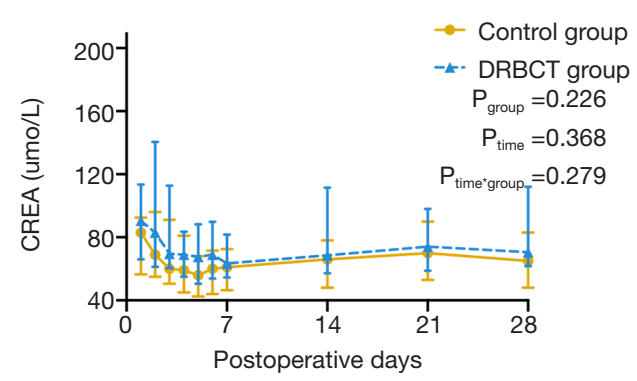

B

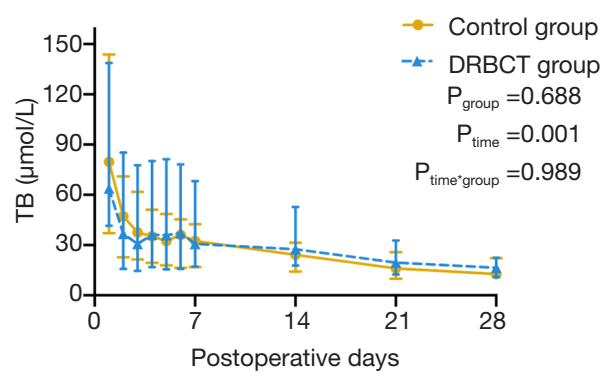

D

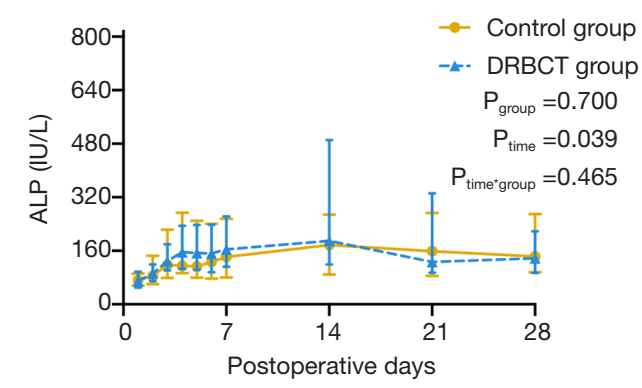

F

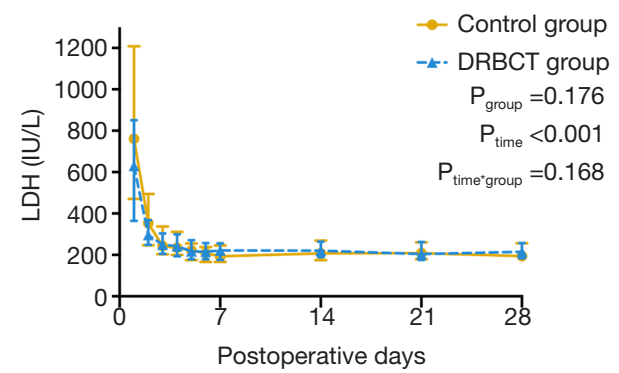

$\mathrm{H}$

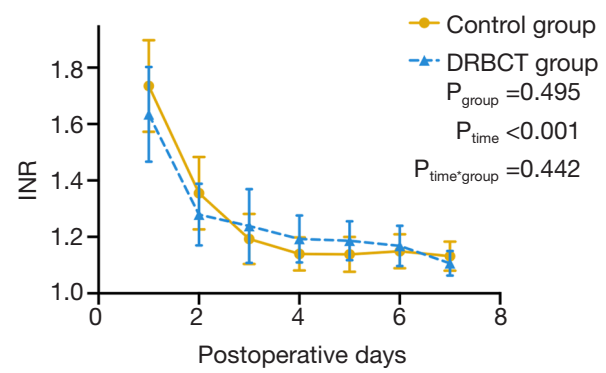

Figure 2 Evolution of postoperative laboratory examination results on days 1, 2, 3, 4, 5, 6, 7, 14, 21 and 28 in the control and DRBCT groups. (A) AST; (B) TB; (C) ALT; (D) ALP; (E) GGT; (F) LDH; (G) CREA; and (H) INR (days 1 to 7). Plots display the median, and whiskers extend to the 25 th and 75 th percentiles. A GEE was used for analysis. *, due to the $\mathrm{P}$ value of the interaction effect being less than 0.05 in picture (A), we further analyzed the simple effects of each timepoint between the two groups by the Mann-Whitney $U$ test. The levels of AST in the first two days after the operation in the DRBCT group were significantly lower than those in the control group (P=0.006 and $\mathrm{P}=0.033$, respectively). DRBCT, donor-specific red blood cell transfusions; TB, Total bilirubin; ALT, alanine aminotransferase; AST, aspartate aminotransferase; ALP, alkaline phosphatase; GGT, gamma-glutamyl transferase; LDH, lactic dehydrogenase; CREA, creatinine; INR, international normalized ratio; GEE, generalized estimating equation. 
A

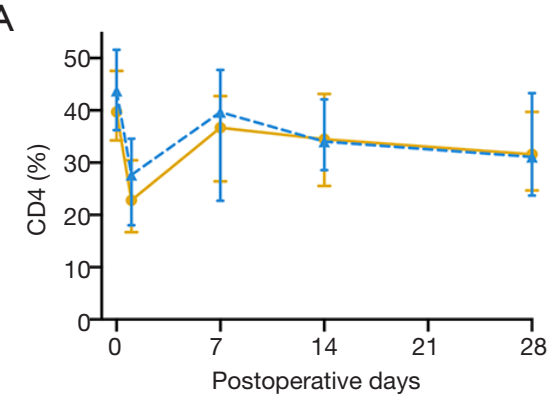

C

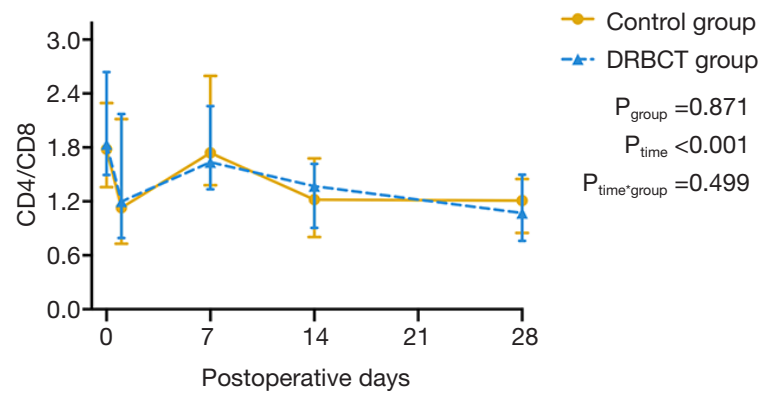

B

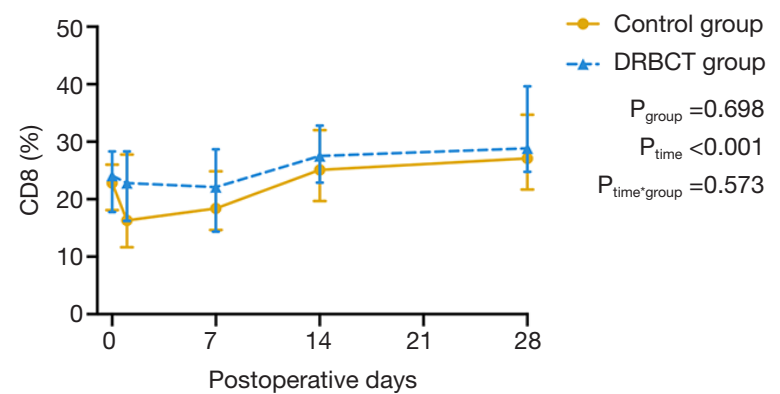

Figure 3 Evolution of T lymphocyte subsets on days 0, 7, 14, 21 and 28 in the control or DRBCT group. (A) CD4 (\%); (B) CD8 (\%); (C) CD4/CD8. Plots display the median, and whiskers extend to the 25th and 75th percentiles. A GEE was used for analysis. No significant difference could be detected between the two groups. DRBCT, donor-specific red blood cell transfusions; GEE, generalized estimating equation.

donors with bacteremia and viremia was contraindicated, and we used mNGS to detect any potential infection, which has the characteristics of high sensitivity and specificity, wide coverage and strong detection ability (24). Donors with ICU stays of more than 7 days were also excluded for potential DRBCT, as prolonged stays in the ICU have been proven to increase the risk of nosocomial infections in deceased donors (25). Notably, the aseptic technique at each step of DRBCT is critical to the prevention of contamination. Moreover, some studies demonstrated that leukocyte depletion filter in combination with autotransfusion devices efficiently eliminate bacteria from the blood (26,27). Though not supposed to eliminate the risk of donor-derived infection, the measures we took in this study resulted in satisfying outcomes. In our results, DRBCT patients did not develop any life-threatening infections, and all postoperative infection events had no evidence of being donor-derived. In addition, no difference in postoperative infections within 1 month was detected between the two groups. These results strongly suggested that DRBCT is safe for recipients.

Interestingly, another important finding of this study was that there was a statistically significant decrease in the peak AST level in the DRBCT group compared to the control group in the first two postoperative days. Some studies have shown that lower AST levels after liver transplantation are associated with superior outcomes $(28,29)$. We deduced that this result may be associated with the decrease in $3^{\text {rd }}$ party pRBCs transfusions. Residual donor WBCs in $3^{\text {rd }}$ party pRBCs may be the primary culprits. Under immunosuppressive states, allogeneic WBCs are not rapidly destroyed by the host's immune system; thus, they may attack the host or the graft, resulting in a poor prognosis (30-32). On the other hand, passenger leukocytes from DBD donors can induce liver allograft tolerance $(33,34)$; thus, residual leukocytes from donor blood may have also had a protective effect on the graft livers in the DRBCT group. But we are not sure whether the leukocytes from the donor's blood will have positive or negative effects on the recipient. Hence, the leukocyte depletion filter was used to remove most of WBC.

Postoperative T-lymphocyte subsets were also monitored in both groups. Perhaps because of the small sample size or other reasons, there was no significant difference between the two groups. It suggested the DRBCT had no extra significant effects on the immune response compared with the control group. Thus, whether intraoperative DRBCT can provide the same immunological protection as 
preoperative DRBCT needs further study.

There are some shortcomings in this study. (I) The sample size was small, and it was not a randomized study. These results will have to be confirmed by further studies with a larger number of subjects. (II) The follow-up time was short, and no long-term results were observed.

In conclusion, this is the first prospective controlled clinical trial that evaluated the effect of DRBCT on DDLT, and our results suggested that DRBCT is a safe and effective procedure to lower the need for supplies from the blood bank. Moreover, it reduced the level of AST after transplantation to a certain extent. Though the greatest limitation to the widespread utilization of DRBCT is ethical barriers, the DRBCT protocol provides a chance for patients without sufficient blood supply to receive lifesaving transplants, not only for the COVID-19 pandemic period but also for other specific times when blood bank resources are restrained. This was a preliminary attempt at DRBCT application, and high-volume and long-term study was required to confirm our results.

\section{Acknowledgments}

The authors thank Dr. Min Jiang for her contribution to statistical analysis and Dr. Junlong Dai for his contribution to graphic jobs.

Funding: This study was supported by grants from the New Clinical Technology Project, West China Hospital, Sichuan University (Grant number: 20HXJS012); Sichuan Province Key Research and Development Project (Grant number: 2020YFS0134) and National Clinical Research Center for Geriatrics, West China Hospital, Sichuan University (Grant number: Z2018B23).

\section{Footnote}

Reporting Checklist: The authors have completed the TREND reporting checklist. Available at https://hbsn. amegroups.com/article/view/10.21037/hbsn-21-190/rc

Data Sharing Statement: Available at https://hbsn. amegroups.com/article/view/10.21037/hbsn-21-190/dss

Conflicts of Interest: All authors have completed the ICMJE uniform disclosure form (available at https://hbsn.amegroups. com/article/view/10.21037/hbsn-21-190/coif). Dr. Lv received grants from Sichuan Province Key Research and Development Project (Grant number: 2020YFS0134). Dr. Yang received grants from the New Clinical Technology Project, West China Hospital, Sichuan University (Grant number: 20HXJS012) and National Clinical Research Center for Geriatrics, West China Hospital, Sichuan University (Grant number: Z2018B23). The other authors have no conflicts of interest to declare.

Ethical Statement: The authors are accountable for all aspects of the work in ensuring that questions related to the accuracy or integrity of any part of the work are appropriately investigated and resolved. The trial was conducted in accordance with the Declaration of Helsinki (as revised in 2013). The study was approved by the Ethics Committee of West China Hospital of Sichuan University (No.: 2020-166) and registered with the Chinese Clinical Trial Registry (ChiCTR2000041375). Written informed consent was obtained from each donor and recipient.

Open Access Statement: This is an Open Access article distributed in accordance with the Creative Commons Attribution-NonCommercial-NoDerivs 4.0 International License (CC BY-NC-ND 4.0), which permits the noncommercial replication and distribution of the article with the strict proviso that no changes or edits are made and the original work is properly cited (including links to both the formal publication through the relevant DOI and the license). See: https://creativecommons.org/licenses/by-nc-nd/4.0/.

\section{References}

1. Hibi T, Wei Chieh AK, Chi-Yan Chan A, et al. Current status of liver transplantation in Asia. Int J Surg 2020;82S:4-8.

2. Chen W, Yadav DK, Bai X, et al. Liver Transplantation from Voluntary Organ Donor System in China: A Comparison between DBD and DCD Liver Transplants. Gastroenterol Res Pract 2019;2019:5736702.

3. Perilli V, Aceto P, Sacco T, et al. Anaesthesiological strategies to improve outcome in liver transplantation recipients. Eur Rev Med Pharmacol Sci 2016;20:3172-7.

4. Strauss AT, Boyarsky BJ, Garonzik-Wang JM, et al. Liver transplantation in the United States during the COVID-19 pandemic: National and center-level responses. Am J Transplant 2021;21:1838-47.

5. Manara AR, Mumford L, Callaghan CJ, et al. Donation and transplantation activity in the UK during the COVID-19 lockdown. Lancet 2020;396:465-6.

6. Wang Y, Yang H, Liu H, et al. Strategies to halt 2019 novel coronavirus (SARS-CoV-2) spread for organ transplantation programs at the Sichuan Academy of 
Medical Science and Sichuan Provincial People's Hospital, China. Am J Transplant 2020;20:1837-9.

7. Wang Y, Han W, Pan L, et al. Impact of COVID-19 on blood centres in Zhejiang province China. Vox Sang 2020;115:502-6.

8. Newton WT, Anderson CB. Planned preimmunization of renal allograft recipients. Surgery 1973;74:430-6.

9. Cochrum KC, Hanes D, Potter D, et al. Donor-specific blood transfusions in HLA-D-disparate one-haplotyperelated allografts. Transplant Proc 1979;11:1903-7.

10. Salvatierra O Jr, Vincenti F, Amend W, et al. Deliberate donor-specific blood transfusions prior to living related renal transplantation. A new approach. Ann Surg 1980;192:543-52.

11. Sollinger HW, Kalayoglu M, Belzer FO. Use of the donor specific transfusion protocol in living-unrelated donorrecipient combinations. Ann Surg 1986;204:315-21.

12. Flye MW, Burton K, Mohanakumar T, et al. Donorspecific transfusions have long-term beneficial effects for human renal allografts. Transplantation 1995;60:1395-401.

13. Marti HP, Henschkowski J, Laux G, et al. Effect of donorspecific transfusions on the outcome of renal allografts in the cyclosporine era. Transpl Int 2006;19:19-26.

14. Alexander JW, Babcock GF, First MR, et al. The induction of immunologic hyporesponsiveness by preoperative donorspecific transfusions and cyclosporine in human cadaveric transplants. A preliminary trial. Transplantation 1992;53:423-7.

15. Otsuka M, Yuzawa K, Takada Y, et al. Long-term results of donor-specific blood transfusion with cyclosporine in living related kidney transplantation. Nephron 2001;88:144-8.

16. Siemionow M, Agaoglu G. Role of blood transfusion in transplantation: a review. J Reconstr Microsurg 2005;21:555-63.

17. Huang JF, Wang HB, Zheng SS, et al. Advances in China's organ transplantation achieved with the guidance of law. Chin Med J (Engl) 2015;128:143-6.

18. Huang J, Millis JM, Mao Y, et al. Voluntary organ donation system adapted to Chinese cultural values and social reality. Liver Transpl 2015;21:419-22.

19. Razonable RR, Humar A. Cytomegalovirus in solid organ transplant recipients-Guidelines of the American Society of Transplantation Infectious Diseases Community of Practice. Clin Transplant 2019;33:e13512.

20. Humar A, Michaels M; AST ID Working Group on Infectious Disease Monitoring. American Society of Transplantation recommendations for screening, monitoring and reporting of infectious complications in immunosuppression trials in recipients of organ transplantation. Am J Transplant 2006;6:262-74.

21. Goel R, Tobian AAR, Shaz BH. Noninfectious transfusionassociated adverse events and their mitigation strategies.
Blood 2019;133:1831-9.

22. Goel R, Petersen MR, Patel EU, et al. Comparative changes of pre-operative autologous transfusions and peri-operative cell salvage in the United States. Transfusion 2020;60:2260-71.

23. Ison MG, Nalesnik MA. An update on donor-derived disease transmission in organ transplantation. Am J Transplant 2011;11:1123-30.

24. Chiu CY, Miller SA. Clinical metagenomics. Nat Rev Genet 2019;20:341-55.

25. Wu TJ, Lee CF, Chou HS, et al. Suspect the donor with potential infection in the adult deceased donor liver transplantation. Transplant Proc 2008;40:2486-8.

26. Liang TB, Li JJ, Li DL, et al. Intraoperative blood salvage and leukocyte depletion during liver transplantation with bacterial contamination. Clin Transplant 2010;24:265-72.

27. Waters JH, Tuohy MJ, Hobson DF, et al. Bacterial reduction by cell salvage washing and leukocyte depletion filtration. Anesthesiology 2003;99:652-5.

28. Eisenbach C, Encke J, Merle U, et al. An early increase in gamma glutamyltranspeptidase and low aspartate aminotransferase peak values are associated with superior outcomes after orthotopic liver transplantation. Transplant Proc 2009; 41:1727-30.

29. Jochmans I, Monbaliu D, Pirenne J. The beginning of an end point: peak AST in liver transplantation. J Hepatol 2014;61:1186-7.

30. Ning S, Heddle NM, Acker JP. Exploring donor and product factors and their impact on red cell posttransfusion outcomes. Transfus Med Rev 2018;32:28-35.

31. Klein HG. Immunomodulatory aspects of transfusion: a once and future risk? Anesthesiology 1999;91:861-5.

32. Han S, Kwon JH, Jung SH, et al. Perioperative Fresh Red Blood Cell Transfusion May Negatively Affect Recipient Survival After Liver Transplantation. Ann Surg 2018;267:346-51.

33. Sun J, Sheil AG, Wang C, et al. Tolerance to rat liver allografts: IV. Acceptance depends on the quantity of donor tissue and on donor leukocytes. Transplantation 1996;62:1725-30.

34. Dai H, Zheng Y, Thomson AW, et al. Transplant Tolerance Induction: Insights From the Liver. Front Immunol 2020;11:1044.

Cite this article as: $\mathrm{Lv} \mathrm{T}, \mathrm{Xu} \mathrm{X}$, Song J, Tan Y, Jiang L, Yang J, He D, Kong L, Zhang W, Chen P, Xiang Q, Zhu T, Wu H, Wen T, Yang J. Use of donor-specific red blood cell transfusions for patients undergoing liver transplantation during the COVID-19 pandemic. HepatoBiliary Surg Nutr 2021;10(4):486-497. doi: 10.21037/hbsn-21-190 